\title{
Correction to: The Role of Temperate Agroforestry Practices in Supporting Pollinators
}

Gary Bentrup, Jennifer Hopwood, Nancy Lee Adamson, Rae Powers, and Mace Vaughan

Correction to:

Chapter 11 in: R. P. Udawatta, S. Jose (eds.), Agroforestry and Ecosystem Services, https://doi.org/10.1007/978-3-030-80060-4_11

An error in the production process unfortunately led to publication of the book before incorporating the below corrections. This has now been corrected and updated throughout the book:

On page 279

In Table 1, the intext figures in the last column have been duplicated as the same in the second column.

The intext figures in the last column of the Table 1 have been corrected.

The updated online version of this chapter can be found at https://doi.org/10.1007/978-3-030-80060-4_11

(C) The Author(s), under exclusive license to Springer Nature Switzerland AG 2022 
Table 1 Common insect pollinator groups

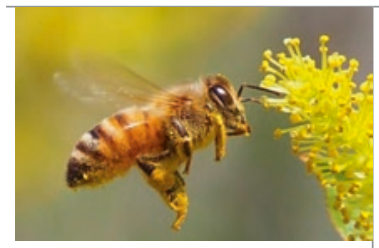

\section{Honey bee}

Order: Hymenoptera

Family: Apidae

Genus and species: Apis mellifera

The European honey bee (native to Europe, Africa, and Asia) is a domesticated species that lives in large perennial social colonies (hives), with division of labor within the colony. Only the queen reproduces, while others gather nectar and pollen to feed brood (larvae) and store food (honey) for the winter. Feral colonies in the United States are somewhat rare; most hives are managed by beekeepers

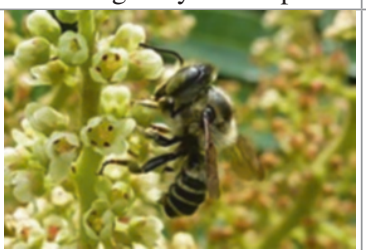

\begin{tabular}{l}
\hline Tunnel-nesting bees \\
\hline Order: Hymenoptera \\
Families: Apidae, Colletidae, \\
Halictidae, Megachilidae
\end{tabular}

Approximately $30 \%$ of solitary bee species nest in tunnels, inside already hollow stems or by chewing into the pithy center of stems, or in existing holes in wood, sometimes man-made. Most tunnel-nesting bees are solitary species

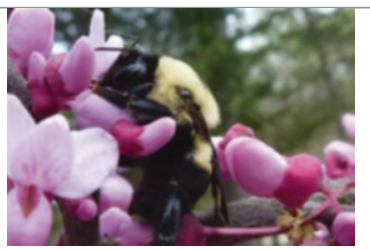

Bumble bees

Order: Hymenoptera

Family: Apidae

Genus: Bombus

Bumble bees form annual social colonies. Queen bumble bees that mated the previous fall start nests in spring and by mid-summer colonies can have dozens or hundreds of workers. They nest in insulated cavities such as under clumps of bunch grass or in old rodent nests.

There are 46 recognized bumble bee species in North America

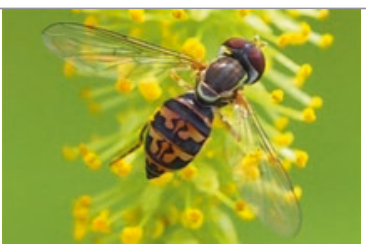

\section{Flower-visiting flies}

Order: Diptera

Families: Anthomyiidae, Bombyliidae, Syrphidae, Tachinidae, others

Flower-visiting flies consume nectar and sometimes pollen. Many hover flies (family Syrphidae) resemble bees or wasps in coloration. Larvae of some species are voracious predators of small insects, like aphids

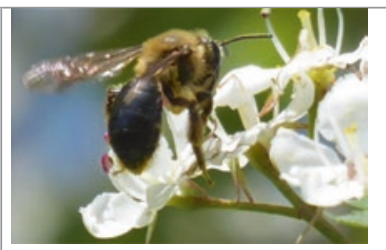

\section{Ground-nesting bees}

Order: Hymenoptera

Families: Andrenidae, Apidae,

Colletidae, Halictidae

Most native bees live solitary

lives, with each female working alone to build her nests and collect and provide food for her offspring. About $70 \%$ of our solitary bee species nest underground, digging slender tunnels in which they build individual cells for each egg and its provisions

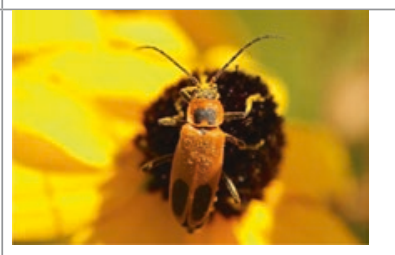

\section{Flower-visiting beetles}

Order: Coleoptera

Families: Cantharidae,

Coccinellidae, Scarabaeidae, others

Flower-visiting beetles consume nectar and pollen, and may also chew on flower parts. Larvae of some species are predatory, hunting other insects (including crop pests) as food, while others are herbivorous or are decomposers 
Table 1 (continued)

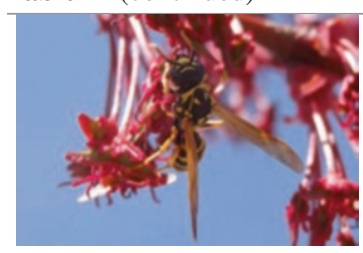

Flower-visiting wasps

Order: Hymenoptera Families: Sphecidae, Vespidae, Tiphiidae, Scoliidae, others

Predatory wasps, most of which are solitary, hunt for prey to bring back to their nest as food for their young. They build nests in cavities or in the ground, and may utilize pieces of grass, mud, or resin in construction of their nest. Adults maintain their energy by consuming nectar and/or pollen, and in the process may also transfer pollen between flowers

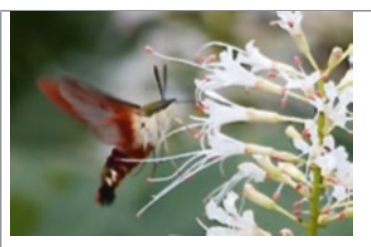

Flower-visiting moths

Order: Lepidoptera Families: Sphingidae, Noctuidae, Arctiidae

Moths, which are often subdued in color and tend to fly at dusk or night, are less visible than other groups, but many are important specialist pollinators of wild plants, while some also pollinate crops. Moths as a group form a critical food source for other wildlife

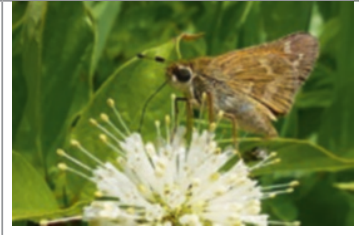

\section{Butterflies}

Order: Lepidoptera

Families: Papilionidae,

Hesperiidae, Pieridae, Lycaenidae, Nymphalidae

With their striking transformation from a chubby plant-chewing caterpillar to a delicate pupa to a graceful nectar-drinking adult, butterflies are some of the most beloved insects. Some species have narrow host plant needs for their caterpillars while others feed on a wide variety of plants

Source: Flower-visiting beetle image by Jennifer Hopwood and remaining images by Nancy Lee Adamson 